\title{
Neurochemical and Cellular Reorganization of the Spinal Cord in a Murine Model of Bone Cancer Pain
}

\author{
Matthew J. Schwei,, ${ }^{1,3}$ Prisca Honore, ${ }^{1,3}$ Scott D. Rogers,, ${ }^{1,3}$ Janeen L. Salak-Johnson, ${ }^{1,3}$ Matthew P. Finke, ${ }^{1,3}$ \\ Margaret L. Ramnaraine, ${ }^{2}$ Denis R. Clohisy, ${ }^{2}$ and Patrick W. Mantyh ${ }^{1,3}$ \\ ${ }^{1}$ Neurosystems Center and Departments of Preventive Sciences, Psychiatry, Neuroscience, and Cancer Center, and \\ 2Department of Orthopaedic Surgery and Cancer Center, University of Minnesota, Minneapolis, Minnesota 55455, and \\ 3Veterans Administration Medical Center, Minneapolis, Minnesota 55417
}

\begin{abstract}
The cancer-related event that is most disruptive to the cancer patient's quality of life is pain. To begin to define the mechanisms that give rise to cancer pain, we examined the neurochemical changes that occur in the spinal cord and associated dorsal root ganglia in a murine model of bone cancer. Twentyone days after intramedullary injection of osteolytic sarcoma cells into the femur, there was extensive bone destruction and invasion of the tumor into the periosteum, similar to that found in patients with osteolytic bone cancer. In the spinal cord, ipsilateral to the cancerous bone, there was a massive astrocyte hypertrophy without neuronal loss, an expression of dynorphin and c-Fos protein in neurons in the deep laminae of the dorsal horn. Additionally, normally non-noxious palpation of the bone with cancer induced behaviors indicative of pain, the internaliza-
\end{abstract}

More than 500,000 patients in the United States died from cancer in 1998, and over 1 million patients suffer from cancer-related pain each year. Pain is the first symptom of cancer in $20-50 \%$ of all cancer patients, and $75-90 \%$ of advanced or terminal cancer patients must cope with chronic pain syndromes related to failed treatment and/or tumor progression (Portenoy and Lesage, 1999). The two most difficult cancer pains to treat are those related to invasion of peripheral nerves and destruction of bone. Breakthrough pain occurs frequently in both of these cancerinduced pain states and represents a serious and debilitating clinical problem (Mercadante and Arcuri, 1998; Portenoy et al., 1999). In total, these two forms of cancer pain account for $\sim 75 \%$ of all chronic cancer pain (Koeller, 1990; Banning et al., 1991; Coleman, 1998; Foley, 1999).

The greatest obstacle to developing new treatments for persistent cancer pain and/or optimally coordinating existing treatments is a paucity of knowledge of the basic neurobiology of cancer pain. There is no well accepted animal model of cancer pain, and the majority of what we know about the

\footnotetext{
Received June 11, 1999; revised Sept. 13, 1999; accepted Sept. 28, 1999.

This work was supported by a Merit Review from the Veterans Administration, National Institutes of Health Grants NS23970, AG11852, and DA 11986, the Roby C. Thompson Jr Endowment in Musculoskeletal Oncology Minnesota Legislative Initiative Fund. The Faxitron imaging system was generously provided by Dr. Kathleen Graber from the Biological Resources Division, National Wildlife Health Center (Madison, W I 53711).

M.S. and P.H. contributed equally to this work.

Correspondence should be addressed to Dr. Patrick W. Mantyh, Neurosystems Center, 18-208 Moos Tower, 515 Delaware Street, Minneapolis, MN 55455. E-mail: manty001@umn.edu.

Copyright (C) 1999 Society for Neuroscience 0270-6474/99/1910886-12\$05.00/0
}

tion of the substance $\mathrm{P}$ receptor, and c-Fos expression in lamina I neurons. The alterations in the neurochemistry of the spinal cord and the sensitization of primary afferents were positively correlated with the extent of bone destruction and the growth of the tumor. This "neurochemical signature" of bone cancer pain appears unique when compared to changes that occur in persistent inflammatory or neuropathic pain states. Understanding the mechanisms by which the cancer cells induce this neurochemical reorganization may provide insight into peripheral factors that drive spinal cord plasticity and in the development of more effective treatments for cancer pain.

Key words: astrocyte; gliosis; nociception; primary afferents; sensitization; osteolysis

neurochemistry of cancer pain has been obtained from clinical studies on how to best manage pain in patients with cancer. Studies on the sensory and sympathetic innervation of human tumors suggest that there is relatively little direct neural innervation of tumors (O'Connell et al., 1998). However, malignant cells are known to secrete prostaglandins, cytokines, epidermal growth factor, transforming growth factor, and platelet-derived growth factor, many of which have been shown to excite primary afferent nociceptors (Mundy, 1988; Goni and Tolis, 1993; Hingtgen and Vasko, 1994; Suzuki and Yamada, 1994; Vasko et al., 1994; Watkins et al., 1994; SafiehGarabedian et al., 1995; Hingtgen et al., 1995; Vasko, 1995; Woolf et al., 1997). Additionally, macrophages, which can represent $>20-30 \%$ of the cells in the tumor mass (McBride, 1986), produce factors such as tumor necrosis factor and interleukin-1, which have been reported to excite primary afferent neurons (Watkins et al., 1994; Safieh-Garabedian et al., 1995; Woolf et al., 1997; Sorkin et al., 1997).

To determine the neurochemical mechanisms that give rise to cancer pain, we have developed a model of bone cancer pain that shares many similarities with human cancer-induced bone pain (Mercadante, 1997). Tumors that most frequently give rise to metastatic bone pain are those originating from breast, lung, ovarian, and prostate cancers (Coleman and Rubens, 1985, 1987). After development of the model, we have characterized the extent of cancer-induced bone destruction, the sensory innervation of the bone, the animal behavior indicative of pain, and the neurochemical changes that occur in the spinal cord and primary afferent neurons that may be involved in the generation and maintenance of cancer pain. 

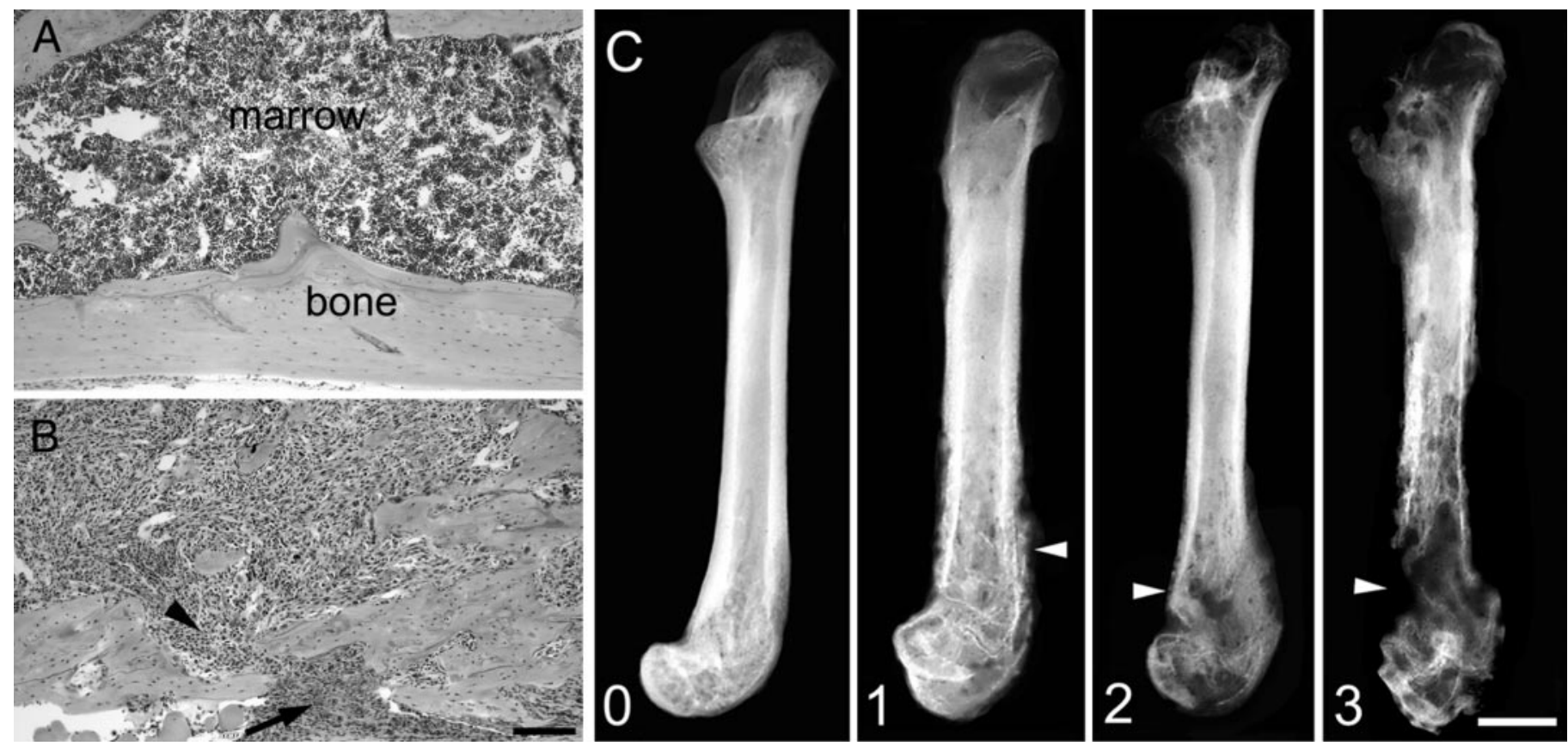

Figure 1. Quantification of bone destruction after injection of osteolytic sarcoma cells into the femoral intramedullary space. Hematoxylin-eosin staining of normal $(A)$ and $21 \mathrm{~d}$ sarcoma-bearing $(B)$ femora, showing the replacement of the darkly stained marrow cells with the more lightly stained sarcoma cells that have induced bone destruction and grown through the bone (arrowhead) and beyond (arrow). Radiographs of the femur ( $C$ ) showing the progressive loss of bone caused by tumor growth. Bone destruction was quantified on a 0-3 scale based on the loss of bone. Images $0-3$ are examples of each state of destruction: 0 , normal bone; 1 , minor loss of bone in medullary canal (arrow); 2, substantial loss of bone in medullary canal with some destruction of the distal femur (arrow); 3, substantial loss of bone in medullary canal with major structural destruction of the distal femur (arrow). Scale bars: $A, B, 200 \mu \mathrm{m} ; C, 2 \mathrm{~mm}$.

\section{MATERIALS AND METHODS}

Strain of mouse and injection of osteolytic cells. Experiments were performed on adult $\mathrm{B} 6 \mathrm{C} 3-\mathrm{Fe}-a / a$ wild-type and $\mathrm{C} 3 \mathrm{H} / \mathrm{HeJ}$ normal mice, 5 - to 6-weeks-old, weighing 20-25 gm (Jackson Laboratories, Bar Harbor, $\mathrm{ME})$. These strains were chosen for their histocompatability with the NCTC 2472 tumor line [American Type Culture Collection (ATCC), Rockville, MD], previously shown to form lytic lesions in bone after intramedullary injection (Clohisy et al., 1995, 1996a).

Tumor cells were maintained in NCTC 135 media containing $10 \%$ horse sera (HyClone, Logan, UT) and passaged weekly according to ATCC recommendations. Tumor-bearing animals were generated as previously published (Clohisy et al., 1996a,b). Briefly, mice were anesthetized with sodium pentobarbital $(50 \mathrm{mg} / \mathrm{kg}$, i.p.), and a left knee arthrotomy was performed. Tumor cells, $10^{5}$ in $20 \mu \mathrm{l}$ of $\alpha$ minimal essential medium ( $\alpha$ MEM) containing $1 \%$ bovine serum albumin (BSA) (tumor; $n=40$ ) or $20 \mu \mathrm{l}$ of $\alpha \mathrm{MEM}$ containing 1\% BSA alone (sham; $n=$ $20)$ were injected directly into the medullary cavity of the distal femur. Additional controls consisted of naïve mice $(n=8)$ and mice with $10^{5}$ 2472 tumor cells $20 \mu \mathrm{l}$ of $\alpha \mathrm{MEM}$ containing $1 \%$ BSA implanted into the quadriceps muscle $(n=10)$. The mice were housed in accordance with National Institutes of Health guidelines and kept in a vivarium, maintained at $22^{\circ} \mathrm{C}$, with a $12 \mathrm{hr}$ alternating light/dark cycle and were given food and water ad libitum. All procedures were approved by the Animal Care Committees at the University of Minnesota.

Behavioral analysis. To evaluate the development of a nociceptive state, animals were observed at $21 \mathrm{~d}$ after injection as they were handled and when they were stimulated with a normally non-noxious mechanical stimulation, which consisted of a light palpation of the distal femur every second for 2 min (for sham and tumor injection inside the femur) and light palpation of the tumor itself (for tumor injected into the quadriceps muscle). Nocifensive behaviors were recorded during and after the $2 \mathrm{~min}$ palpation period. Each animal was given a score of $0-5$. While the injected hindlimb was being palpated, the scoring of each animal was characterized as follows: no reaction during palpation $(0)$; guarding of the hindlimb (1); guarding and strong withdrawal of the hindlimb (2); guarding, strong withdrawal, and fighting (3); guarding, strong withdrawal, fighting, and audible vocalization (4); and guarding, strong withdrawal, fighting, audible vocalization, and intense biting (5).
Killing and processing of tissue. Animals were killed $21 \mathrm{~d}$ after tumor implantation, the spinal cords and dorsal root ganglia (DRGs) were processed for immunohistochemical analysis, and femora were processed for evaluation of bone destruction. Twenty-one days was chosen as the time point because significant, but variable, osteolysis had previously been observed between 14 and $21 \mathrm{~d}$ after injection of the 2472 osteolytic sarcoma cells (Clohisy et al., 1995). In some animals, the cancer bearinglimb was palpated 5 min [substance $\mathrm{P}$ receptor (SPR) internalization] or $1 \mathrm{hr}$ (c-Fos expression) before killing. After these manipulations, the animals were deeply anesthetized with pentobarbital $(50 \mathrm{mg} / \mathrm{kg}$, i.p.) and perfused intracardially with $12 \mathrm{ml}$ of $0.1 \mathrm{M}$ PBS followed by $20 \mathrm{ml}$ of $4 \%$ formaldehyde in PBS. Both ipsilateral and contralateral femora, spinal cord segments L1-S2, and the L4 and L5 DRGs were removed, post-fixed for $16 \mathrm{hr}$ in the perfusion fixative, and cryoprotected for $24 \mathrm{hr}$ in $30 \%$ sucrose in $0.1 \mathrm{M}$ PBS.

Assessing the extent of bone destruction. The extent of bone destruction (osteolysis) in tumor-injected femora was radiologically assessed using either standard x-ray film ( TMG/RA; Eastman Kodak, Rochester, NY) or Faxitron analysis (Specimen Radiography System, model MX-20; Faxitron x-ray Corporation, Wheeling, IL) using Kodak film X-OmatTL. Radiographs of the femur (Fig. 1C) revealed loss of bone density caused by tumor osteolysis. The loss of bone density was quantified on a scale of $0-3$. Images $0-3$ are examples of each state of destruction: (0) normal bone; (1) minor loss of bone in medullary canal; (2) substantial loss of bone in medullary canal with some destruction of the distal femur; and (3) substantial loss of bone in medullary canal with major structural destruction of the distal femur. As in humans with osteolytic sarcoma, in mice where there has been significant bone destruction, the cancer cells have frequently broken through the bone and have formed a tumor mass outside the bone and periosteum. In selected mice we desired to further examine the extent of bone destruction (Fig. $1 A, B$ ), femora were demineralized in 10\% EDTA for 3 weeks and processed for routine paraffin histology to visualize the extent of tumor infiltration and destruction of the bone (Witzel et al., 1992).

Immunohistochemistry. Serial frozen spinal cord sections, $60-\mu \mathrm{m}$-thick, were cut on a sliding microtome, collected in PBS, and processed as free-floating sections. DRGs were embedded in TissueTek, cut on a freezing microtome at a thickness of $15 \mu \mathrm{m}$, and collected and processed 
on gelatin-coated slides. The periosteum was teased off the bone and processed as a whole mount.

Tissue sections were incubated for $30 \mathrm{~min}$ at room temperature in a blocking solution of $1 \%$ normal donkey serum in PBS with $0.3 \%$ Triton$\mathrm{X} 100$ and then incubated overnight at room temperature in the primary antiserum. Markers of (1) primary afferent fibers, substance P (SP; polyclonal rat anti-SP; 1:2000; PharMingen, San Diego, CA), isolectin B4 (IB4; Bandeiraea simplicifolia; 1:180; Sigma, St. Louis, MO), and neuropeptide Y (NPY; polyclonal rabbit anti-NPY; 1:5000; Sigma); (2) spinal cord neurons, substance $\mathrm{P}$ receptor (SPR; polyclonal rabbit antiSPR; 1:5000; raised in our laboratory), neuronal marker (NeuN; polyclonal rat anti-NeuN; 1:75; Chemicon, Temecula, CA), protein kinase C gamma (PKC $\gamma$; polyclonal rabbit anti-PKC $\gamma$; 1:10,000; Santa Cruz Biotechnology, Santa Cruz, CA), dynorphin (DYN; polyclonal guinea pig anti-DYN; 1:10,000; gift from Dr. F. Porreca, University of Arizona), and c-Fos protein (c-Fos; polyclonal rabbit anti-Fos; 1:30,000; Santa Cruz Biotechnology); (3) motor neurons, NeuN, and choline acetyl transferase (ChAT; polyclonal rabbit anti-ChAT; 1:1000; Chemicon); (4) astrocytes, glial fibrillary acidic protein (GFAP; polyclonal rabbit anti-GFAP; 1:600; Dakopatts, Copenhagen, Denmark); and (5) microglia, OX-42 (polyclonal rat anti-Ox42; 1:40; Chemicon) were used to stain spinal cord sections. DRG sections were stained with SP and IB4 and periosteum with calcitonin gene-related peptide (CGRP; 1:15,000; Sigma). After incubation, tissue sections were washed three times for $10 \mathrm{~min}$ in PBS and incubated in the secondary antibody solution for $3 \mathrm{hr}$ at room temperature. Secondary antibodies conjugated to fluorescent markers $\mathrm{Cy} 3$ and FITC were used at 1:600 and 1:150, respectively. Finally, the sections were washed three times for $10 \mathrm{~min}$ in PBS, mounted on gelatin-coated slides, air-dried, dehydrated via an alcohol gradient (70, 90, and $100 \%$ ), cleared in xylene, and coverslipped. To confirm the specificity of primary antibodies, controls included preabsorption with the corresponding synthetic peptide or omission of the primary antibody. To control for the possibility that staining intensities might vary between experiments, control sections of normal mouse spinal cord were included in each run of staining and served as a standard for immunofluorescence measurements.

Quantification of immunofluorescence levels and SPR internalization. Using an MRC-1024 confocal imaging system (Bio-Rad, Hercules, CA) and an Olympus BH-2 microscope equipped for epifluorescence (Mantyh et al., 1995), sections from the lumbar spinal cord and DRGs were analyzed by fluorescent and confocal microscopy to characterize immunofluorescence levels, number of immunoreactive cells, and palpationinduced SPR internalization and spinal c-Fos expression.

Analyses were performed on the spinal cord at the lumbar level (L4) and on the L4 DRG because L4 DRG is one of the main groups of primary afferent neurons innervating the hindlimb (Molander et al., 1984; Molander and Grant, 1985; LaMotte et al., 1991). In addition, after palpation of the femur with tumor, SPR internalization and c-Fos protein expression were mainly observed at the L4 level.

Immunofluorescence intensity measurements were obtained using a 12 bit SPOT2 digital camera (Diagnostic Instruments, Sterling Heights, MI) on an Olympus BX-60 fluorescence microscope with Image Pro Plus version 3.0 software (Media Cybernetics, Silver Spring, MD). The response of the digital camera was measured using 540/560 nm Inspeck fluorescent bead standards (Molecular Probes, Eugene, OR). A ratio was established between the output of the camera and a given relative fluorescence of the beads. The camera response was determined to be linear, thus establishing that a doubling of the camera grayscale output represents a doubling of label present in the tissue.

For SPR internalization, sagittal sections were viewed through a $1 \mathrm{~cm}^{2}$ eyepiece grid divided into $1001 \times 1 \mathrm{~mm}$ units. In cell bodies that express the SPR but have not internalized the SPR, SPR immunoreactivity is distributed on the plasma membrane. In contrast, in the neurons that have internalized the SPR, the cytoplasm contain bright, SPRimmunoreactive endosomes. An endosome was defined as an intense SPR-immunoreactive intracellular organelle between 0.1 and $0.7 \mu \mathrm{m}$ in diameter that was clearly not part of the external plasma membrane. In the normal unstimulated mouse spinal cord, nearly every lamina I neuron contained less than five SPR-immunoreactive endosomes per cell body. In the present study, neurons containing $\geq 20$ endosomes were considered to be internalized. Importantly, because neurons with $<20$ endosomes were not counted as having undergone significant SPR internalization, it is possible that subtle changes in the magnitude of internalization were underestimated.

To study the laminar distribution of c-Fos and dynorphin expression, four regions were defined: superficial dorsal horn (laminae I-II), nucleus proprius (laminae III-IV), neck of the dorsal horn (laminae V-VI), and the ventral gray (laminae VII-X). The number of c-Fos and dynorphinpositive neurons were counted in these four regions in 10 randomly selected sections from the L4 segment in each animal. Results are given as mean number of c-Fos or dynorphin-positive neurons per section per group.

Statistical tests. One-way ANOVA was used to compare immunohistochemical measures (immunofluorescence levels and counts) between the experimental groups. To evaluate the correlation between bone destruction and behavioral changes, SPR internalization, c-Fos expression, dynorphin, and GFAP immunofluorescence at the spinal level, a Pearson's correlation coefficient was performed. For multiple comparisons, the Fisher's protected least significant difference (PLSD) post hoc test was used. Significance was at $p<0.05$. In all cases, the investigator responsible for plotting, measuring, and counting, was blind.

\section{RESULTS}

\section{Evaluation of tumor growth, bone destruction, and tumor-induced behavioral changes}

Twenty-one days after injection, bone destruction was not observed in animals that received sham injection into the femur or animals that received injection of 2472 sarcoma cells into the quadriceps muscle. In animals receiving injection of 2472 sarcoma cells into the quadriceps muscle, the tumor had grown to a size of 5-12 mm in diameter and had displaced nearby muscle groups. The tumor appeared to be encapsulated by connective tissue so that the surrounding bone or muscle was not destroyed. In contrast, various degrees of bone destruction were observed in animals that had received injection of 2472 sarcoma cells into the femur. As shown in Figure 1, sarcoma cells injected into the femoral intramedullary canal induced significant bone destruction. In cases of severe bone destruction (bone destruction score of 3 ), the tumor penetrated the bone and periosteum and grew outside the bone (Fig. $1 A, B$ ). At $21 \mathrm{~d}$ after injection of sarcoma cells into the femur, radiological evaluation of bone destruction showed that $39 \%(n=14)$ of the animals had a bone destruction score of $3,24 \%(n=9)$ had a bone destruction score of $2,16 \%$ $(n=6)$ had a score of 1 , and $21 \%(n=8)$ did not show any visible signs of osteolysis (Fig. 1C). Although it was highly variable, in animals with no sign of bone destruction, the size of the knee measured with a caliper was $4 \mathrm{~mm}$ (no difference between ipsilateral and contralateral sides), whereas in animals with pronounced osteolysis (score of 3 ), there was a significant increase in the size of the knee area $(8 \mathrm{~mm} ; p<0.02$ compared to contralateral side), showing that significant tumor growth had also occurred outside the bone.

Behaviorally, animals with either sham injection into the femur or sarcoma injection into the quadriceps showed no signs of ongoing pain (guarding the hindlimb) nor any pain during palpation of the hindlimb (sham injection) or palpation of the tumor (quadriceps injection). In contrast, animals injected with 2472 sarcoma cells in the femur showed guarding when handled. Additionally, normally non-noxious palpation of the knee or tumor, which did not induce any behavioral response in the sham and quadriceps-injected animals, induced a nocifensive behavioral response in animals with injection of 2472 sarcoma cells into the femur. This nocifensive behavioral response was positively and significantly correlated with the extent of bone destruction $(r=0.67 ; p<0.007)$.

\section{Alterations in primary afferent sensory neurons $21 \mathrm{~d}$ after tumor injection}

In a normal murine femur, CGRP fibers are present in mineralized bone, the marrow, and in the periosteum surrounding the 
Table 1. Neurochemical signature of bone cancer pain

\begin{tabular}{|c|c|c|c|c|}
\hline & Sham-bone & Quadriceps & Bone & Bone \\
\hline & $\begin{array}{l}\text { Media injection } \\
\text { ipsilateral side }\end{array}$ & $\begin{array}{l}\text { Tumor injection } \\
\text { ipsilateral side }\end{array}$ & $\begin{array}{l}\text { Tumor injection } \\
\text { ipsilateral side }\end{array}$ & $\begin{array}{l}\text { Tumor injection } \\
\text { contralateral side }\end{array}$ \\
\hline \multicolumn{5}{|l|}{ Spinal cord } \\
\hline \multicolumn{5}{|l|}{ Primary afferents } \\
\hline SP Lam I-II (IF) & $100.0 \pm 13.2$ & $129.7 \pm 18.6$ & $111.8 \pm 5.0$ & $105.3 \pm 5.6$ \\
\hline IB4 Lam IIi (IF) & $100.0 \pm 12.7$ & $104.8 \pm 17.3$ & $143.7 \pm 12.8$ & $140.3 \pm 13.3$ \\
\hline NPY Lam I-II (IF) & $100.0 \pm 15.6$ & $112.1 \pm 9.4$ & $110.4 \pm 4.0$ & $117.1 \pm 10.2$ \\
\hline DYN Lam I-II (IF) & $100.0 \pm 7.7$ & & $117.4 \pm 7.5$ & $103.3 \pm 0.6$ \\
\hline SPR Lam I-II (IF) & $100.0 \pm 29.6$ & $100.6 \pm 8.8$ & $143.4 \pm 26.8$ & $153.3 \pm 27.5$ \\
\hline PKC $\gamma$ Lam IIi (IF) & $100.0 \pm 14.7$ & $100.1 \pm 21.1$ & $95.8 \pm 22.7$ & $85.3 \pm 27.9$ \\
\hline NeuN Lam I-X (IF) & $100.0 \pm 9.5$ & $98.9 \pm 4.2$ & $93.4 \pm 4.2$ & $96.9 \pm 4.4$ \\
\hline DYN Lam III-VI (count) & $0.0 \pm 0.0$ & & $5 \pm 1^{* * *}$ & $0.0 \pm 0.0$ \\
\hline \multicolumn{5}{|l|}{ Lam I-II (count) } \\
\hline Basal Fos-IR & $5.2 \pm 2.1$ & $0.7 \pm 0.5$ & $12.6 \pm 2.3^{*}$ & $3.2 \pm 1.3$ \\
\hline Palpation induced Fos-IR & $11.0 \pm 3.6$ & $0.5 \pm 0.5$ & $32.0 \pm 6.0^{* *}$ & $6.5 \pm 2.3$ \\
\hline \multicolumn{5}{|l|}{ Lam V-VI (count) } \\
\hline Basal Fos-IR & $16.7 \pm 3.2$ & $1.0 \pm 1.0$ & $42.2 \pm 4.8^{* * *}$ & $14.5 \pm 4.6$ \\
\hline Palpation induced Fos-IR & $10.7 \pm 4.2$ & $1.5 \pm 1.5$ & $32.7 \pm 6.3^{* * *}$ & $10.3 \pm 5.2$ \\
\hline \multicolumn{5}{|l|}{ Glia } \\
\hline GFAP Lam I-X (IF) & $100.0 \pm 25.6$ & $84.2 \pm 26.9$ & $359.9 \pm 95.8^{* *}$ & $95.3 \pm 27.2$ \\
\hline Ox42 Lam I-X (IF) & $100.0 \pm 1.0$ & $103.7 \pm 0.5$ & $99.6 \pm 2.5$ & $99.7 \pm 2.1$ \\
\hline \multicolumn{5}{|l|}{ Motoneurons } \\
\hline NeuN motoneurons (count) & $100.0 \pm 5.8$ & $104.9 \pm 2.6$ & $93.5 \pm 3.2$ & $96.3 \pm 3.0$ \\
\hline ChAT motoneurons (count) & $100.0 \pm 0.6$ & $108.5 \pm 9.1$ & $102.1 \pm 4.6$ & $98.4 \pm 5.9$ \\
\hline \multicolumn{5}{|l|}{ DRG } \\
\hline SP (\% of small neurons) & $31.0 \pm 4.9$ & $29.8 \pm 3.2$ & $25.6 \pm 2.5$ & $33.7 \pm 4.2$ \\
\hline IB4 (\% of small neurons) & $73.3 \pm 3.1$ & $62.9 \pm 0.8$ & $72.8 \pm 5.8$ & $72.1 \pm 6.8$ \\
\hline
\end{tabular}

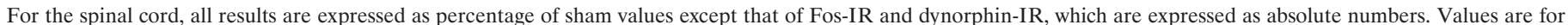

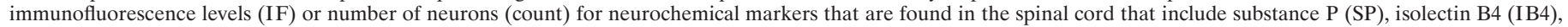

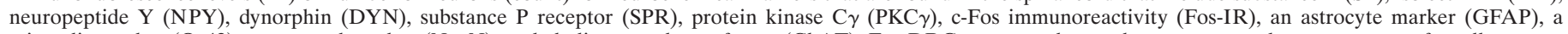

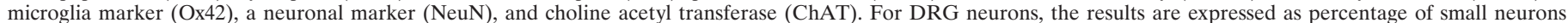

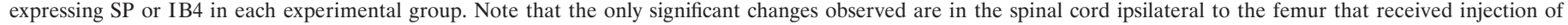

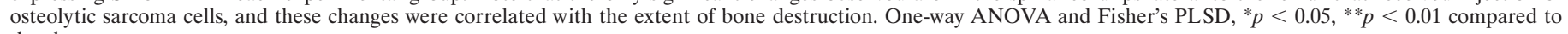
the sham group.

bone (Iwasaki et al., 1995). Although CGRP fibers are found in all aspects of the bone, the structure with the richest CGRP innervation is the periosteum. Within the periosteum, CGRP fibers form a dense meshwork of interdigitating fibers, and when these fibers penetrate mineralized bone, they usually follow blood vessels. Although the periosteum is highly innervated, only occasional CGRP fibers were observed in the 2472 tumor mass in the intramedullary space of the bone, and those that were present were associated with blood vessels. The development of the sarcoma did not induce any obvious changes in the innervation of mineralized bone or periosteum, although the destruction of both mineralized bone and periosteum made it difficult to quantify changes that might have taken place. In naïve or sham-injected animals, $31 \pm 5 \%$ of small cells were SP-immunoreactive (IR), whereas $73 \pm 3 \%$ of small DRG neurons were IB4-IR, and these percentages did not significantly change in animals injected with sarcoma cells within the femur or within the quadriceps muscle (Table 1).

\section{Alterations in the spinal cord neurochemistry $21 \mathrm{~d}$ after tumor injection}

Subpopulations of sensory neurons express either SP or can be labeled with the isolectin IB4. SP-expressing primary afferent neurons terminate in laminae I-II of the dorsal horn of the spinal cord and neurons that are labeled with isolectin IB4 are confined to lamina II. As in the DRGs, SP and IB4 immunofluorescent levels in the superficial spinal cord were not statistically different when comparing naïve, sham injections into the femur, sarcoma injection into the quadriceps muscle, or sarcoma injection into the femur (Fig. 2E, Table 1). In these four groups of animals, there was no change in NPY-IR or dynorphin-IR in laminae I-II (Fig. 2B, Table 1) nor any changes in the number or immunofluorescence levels of spinal cord neurons labeled with SPR in laminae I-II and III-IV, PKC $\gamma$ in lamina II (Fig. $2 F$ ), or NeuN in the overall gray matter (Table 1). Additionally, the number of motor neurons labeled with NeuN or ChAT remained unchanged in these four groups (Table 1).

In contrast, there were three significant changes that occurred in the spinal cord of animals that received injection of 2472 sarcoma cells into the femur that were not observed in any of the other experimental groups. First, there was expression of dynorphin in a subpopulation of dorsal horn neurons located in laminae III-VI ( $5 \pm 1$ DYN-IR neurons per section; $p<0.001$ compared to sham values of $0 \pm 0$ DYN-IR neurons per section; Fig. $2 B$, Table 1). This dynorphin accumulation was observed only in the spinal cord segments L3-L5 ipsilateral to bone destruction and peaked at spinal cord segment L4. This expression of dynorphin by neurons in the deep laminae of the spinal cord was positively 

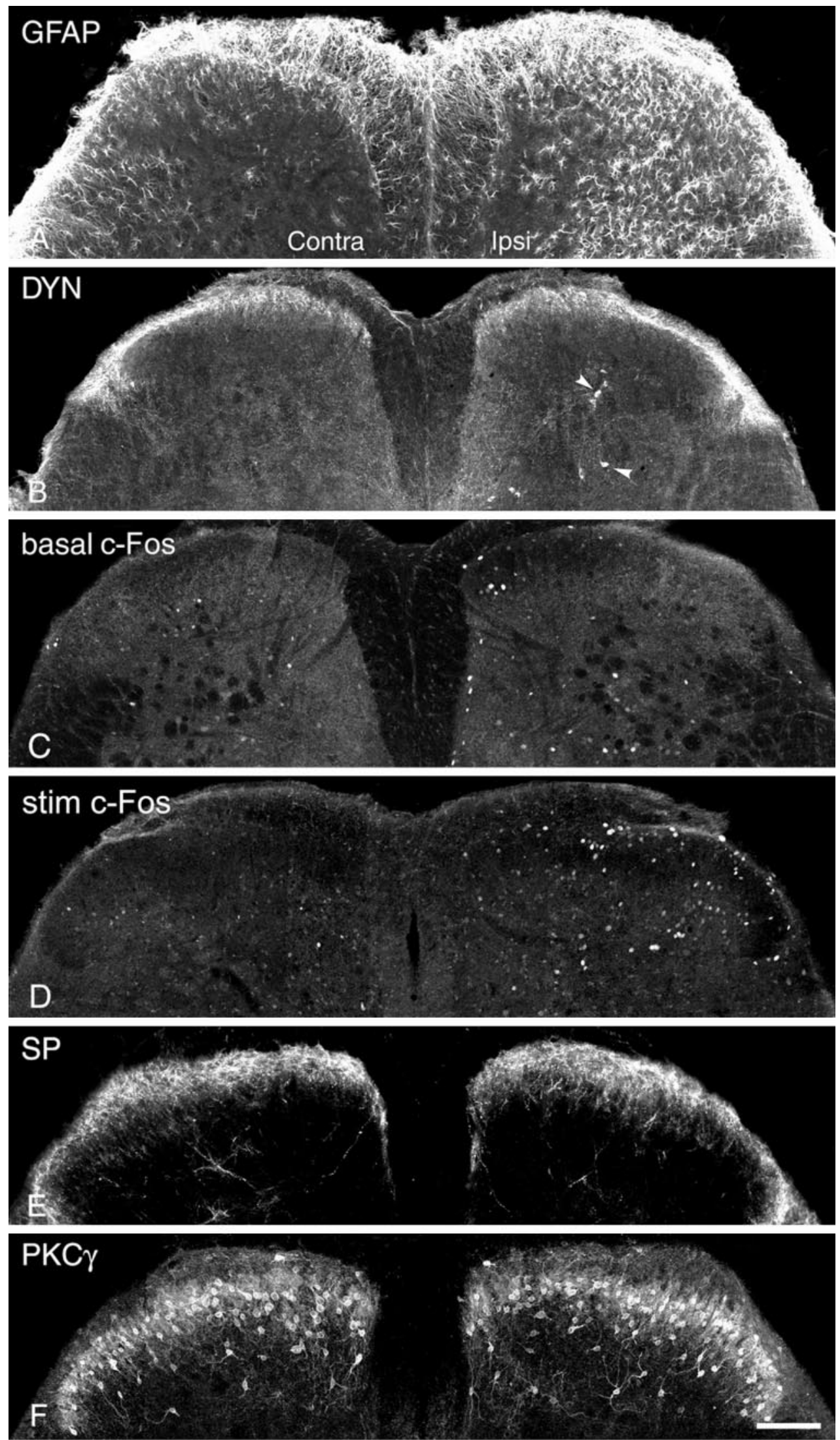

Figure 2. Neurochemical changes in the dorsal horn of the spinal cord $21 \mathrm{~d}$ after unilateral injection of an osteolytic sarcoma in the intramedullary space of the femur. Confocal images of coronal sections of the L4 spinal cord illustrate the distribution of the astrocyte marker GFAP $(A)$; DYN with arrows indicating the cell bodies expressing this pro-hyperalgesic peptide $(B)$; c-Fos protein in the basal unstimulated state $(C)$; (Figure legend continues) 
and significantly correlated to the extent of bone destruction $(r=0.97 ; p<0.0001)$.

The second major change was in the expression of c-Fos protein in the spinal cord. In the unstimulated mouse, there are relatively few spinal neurons that express the c-Fos protein. Thus, very few Fos-IR neurons were observed in the spinal cord in naïve animals, animals that received sham injection into the femur, or animals that received injection of 2472 sarcoma cells into the quadriceps muscle (Table 1). In contrast, $21 \mathrm{~d}$ after injection of 2472 sarcoma cells into the femur, without any additional somatosensory stimulation, there was a significant increase in the number of spinal cord neurons that express c-Fos protein in laminae V-VI of the dorsal horn (Fig. 2C, Table 1). This c-Fos expression was observed only in the spinal cord segments L3-L5, and the number of neurons expressing c-Fos peaked at spinal cord segment L4, ipsilateral to bone destruction. This increase was positively and significantly correlated with the extent of bone destruction $(r=0.95 ; p<0.0002$; see Fig. $4 A)$.

The third and most striking neurochemical change that occurred in animals injected with 2472 sarcoma cells in the femur was a massive astrogliosis that occurred in the ipsilateral spinal cord segments that receive primary afferent input from the cancerous femur. This astrogliosis was quantified using the astrocyte marker GFAP. In the animals with sarcoma injection into the femur, overall GFAP immunofluorescence levels were $359.9 \pm$ $95.8 \%$ of sham values $(p<0.01$; Figs. $2 A, 3 A)$. This increase in GFAP labeling was observed in lumbar segments L2-L5 with a peak in L4 (Fig. 3A), ipsilateral to bone destruction, and was not associated with any loss of neurons because the labeling with the neuronal marker NeuN remained unchanged (Fig. 3D,E). This increase in GFAP labeling was highest in laminae V-VI, but a significant increase was also observed throughout all the spinal laminae [in sarcoma-injected animals, GFAP levels were $137.4 \pm$ $9.5 \%$ (laminae I-II), $238.9 \pm 36.1 \%$ (laminae III-IV), $655.9 \pm$ $141.2 \%$ (laminae V-VI), $493.5 \pm 126.1 \%$ (ventral region) of sham values; $p<0.05 ; p<0.05 ; p<0.001$; and $p<0.001$, respectively]. This increase in GFAP appeared to represent a hypertrophy of the astrocytes because the cell bodies were enlarged, and the distal processes of the astrocytes were longer and exhibited extensive arborization as compared to sham animals, animals with injection of 2472 sarcoma cells into the quadriceps muscle, or the contralateral spinal cord of the animals receiving injection of 2472 sarcoma cells into the femur (Fig. 3B,D). This astrogliosis was positively and significantly correlated to the extent of bone destruction $(r=0.695 ; p<0.0001$; Fig. $4 A)$. In contrast, the level of OX-42 immunoreactivity that labels microglia remained unchanged (Table 1).

\section{Effects of normally non-noxious palpation in the spinal cord in normal mice and mice with bone cancer}

In the spinal cord, the highest concentration of SPR-expressing cells is found in lamina I with other SPR-expressing cells also being present in laminae III-V and X. In the normal unstimulated animal, most of the SPR-IR is associated with the plasma membrane with few SPR-IR endosomes present in the cytoplasm.
Non-noxious palpation of the distal femur did not induce spinal SPR internalization in naïve animals or animals with sham injection into the femur, nor did non-noxious palpation of the tumor in animals where the sarcoma cells had been injected into the quadriceps muscle (Figs. $5 A, 6 A$ ). In contrast, this normally non-noxious stimulation induced SPR internalization in a significant number of SPR-expressing lamina I neurons in animals that had received sarcoma injection into the femur (Fig. 5B). SPR internalization was observed in both the dendrites and cell body of SPR neurons localized in lumbar segments L3-L5 ipsilateral to the palpation. After a normally non-noxious stimulation, $63 \pm 8 \%$ of the SPR-expressing lamina I neurons showed SPR internalization (Fig. $6 A ; p<0.01$ compared to sham values). No SPR internalization was detected in SPR-IR neurons located in deeper laminae. The number of SPR-internalized lamina I neurons was positively and significantly correlated to the extent of bone destruction $(r=0.91 ; p<0.002)$.

Normally non-noxious mechanical stimulation (palpation) of the distal femur also induced a significant increase in the number of c-Fos-expressing lamina I neurons in animals with sarcoma cells injected into their femur, whereas the same stimulation did not induce any significant c-Fos expression in animals that received sham injection in the femur or in animals that received sarcoma injection in the quadriceps muscle (Fig. 6B, Table 1). Non-noxious palpation induced $32 \pm 6$ of c-Fos-IR lamina I neurons per section ( $p<0.01$ compared to sham values and $p<$ 0.001 compared to contralateral side). Non-noxious palpation induced c-Fos expression in neurons located principally in the lateral part of laminae I-II in lumbar segments L3-L5, peaking at L4 (Fig. 3D) which has previously been shown to correspond to the region of the dorsal horn that receives primary afferent input from the femur. The number of palpation-induced c-Fos-IR lamina I neurons was positively and significantly correlated to the extent of bone destruction $(r=0.78 ; p<0.005)$.

\section{DISCUSSION}

\section{A model for bone cancer pain?}

In assessing any experimental animal model, it is important to determine how well the model approximates the human disease. The most common symptom of bone metastases in humans is bone pain. Bone destruction, which causes this pain, can lead to pathological fractures and/or hypercalcemia (Lipton, 1997; Mundy, 1997; Coukell and Markham, 1998; Fulfaro et al., 1998). Over weeks or months, as the tumor grows and stimulates bone destruction, the pain progressively becomes more severe. Cancerinduced bone destruction causes an ongoing pain that is referred to the affected bone and is characterized as initially constant and dull in character. With increased bone destruction and time, the pain intensifies and can incapacitate the affected individual. As bone destruction progresses, acute pain is frequently observed when the involved bone is moved or palpated. Breakthrough pain, which is an intermittent episode of extreme pain, occurs spontaneously or more commonly by weight bearing or movement of the affected bone (Mercadante and Arcuri, 1998; Portenoy et al.,

\section{$\leftarrow$}

c-Fos protein at $1 \mathrm{hr}$ after normally non-noxious palpation of the knee $(D)$; SP $(E)$; PKC $\gamma$ isoform $(F)$. Note that the major changes occur in the spinal cord ipsilateral to the cancer-bearing femur and include an increase in GFAP $(A)$, DYN $(B)$, basal c-Fos expression $(C)$, and increased expression of c-Fos in neurons located in laminae I and II after normally non-noxious palpation $(D)$. In contrast, levels of SP $(E)$, a peptide contained in primary afferent neurons that is frequently upregulated in persistent pain states, and $\mathrm{PKC} \gamma(F)$, a kinase that is expressed in a subset of spinal neurons in lamina II and that is frequently upregulated in neuropathic pain states, remained unchanged. These images are from $60-\mu \mathrm{m}$-thick tissue sections projected from 10 optical sections acquired at $5 \mu \mathrm{m}$ intervals with a $20 \times$ lens. Scale bar, $200 \mu \mathrm{m}$. 

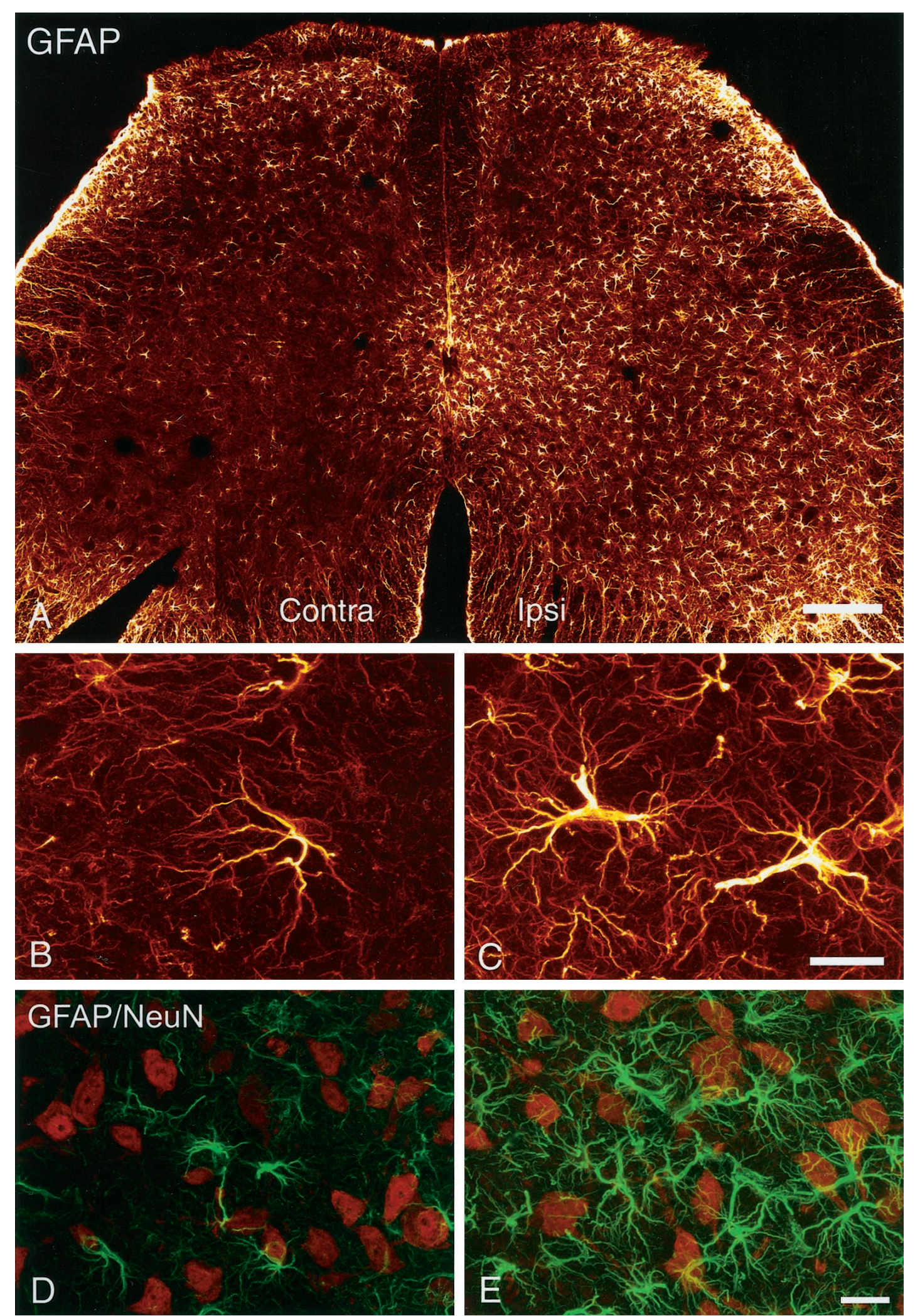

Figure 3. Confocal images showing the increase in the astrocyte marker GFAP in coronal sections of the L4 spinal cord $21 \mathrm{~d}$ after injection of osteolytic sarcoma cells into the intramedullary space of the femur. In $A-C$, the GFAP is bright orange, and in $D$ and $E$, GFAP is green, and the NeuN staining (which labels neurons) is red. A low-power image $(A)$ shows that the upregulation of GFAP is almost exclusively ipsilateral to the femur with cancer, with a small increase in the contralateral spinal cord in lamina X. Higher magnification of GFAP contralateral $(B, D)$ and ipsilateral $(C, E)$ to the femur with cancer shows that on the ipsilateral side, there is marked hypertrophy of astrocytes characterized by an increase in both the size of the astrocyte cell bodies and the extent of the arborization of their distal processes. Additionally, this increase in GFAP (green) is observed without a detectable loss of neurons, because NeuN (red) labeling remains unchanged $(D, E)$. These images, from $60-\mu \mathrm{m}$-thick tissue, are projected from six optical sections acquired at $4 \mu \mathrm{m}$ intervals with a $20 \times$ lens. Scale bars: $A, 200 \mu \mathrm{m}$ (projected from 12 optical sections acquired at $0.8 \mu \mathrm{m}$ intervals with a $100 \times$ lens); $B, C, 20 \mu \mathrm{m}$ (projected from 10 optical sections acquired at $0.8 \mu \mathrm{m}$ intervals with a $60 \times$ lens); $D, E, 30 \mu \mathrm{m}$. 

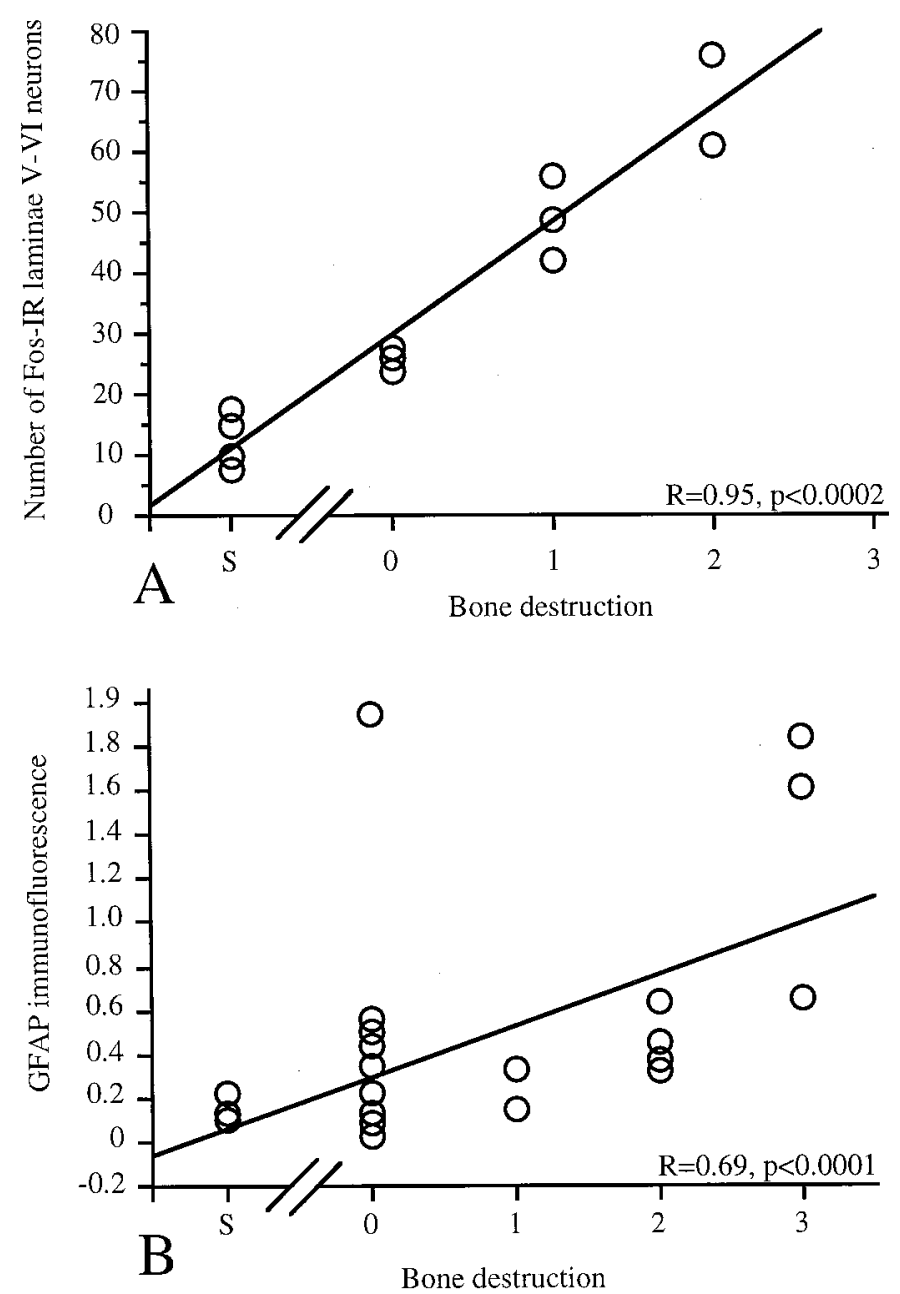

Figure 4. Correlation of bone destruction with spinal cord GFAP immunofluorescence and with basal spinal c-Fos expression. Results are expressed as correlation coefficient $(R)$ between bone destruction as defined in Figure 1 (score $0-3 ; S$, sham) and the number of neurons expressing c-Fos in laminae V-VI $(A)$ and GFAP immunofluorescence in laminae I-X $(B)$. Note that there is a significant correlation between the extent of bone destruction with both basal c-Fos expression and GFAP immunofluorescence.

1999). In humans, the extent of bone destruction, and particularly ongoing osteolytic activity, is correlated with the severity and the frequency of breakthrough pain (Adami, 1997).

The murine model we have developed appears to share many features of human bone cancer-induced pain. The osteolytic sarcoma cell line used in this study aggressively destroys bone and provides localized pathological findings found in human osteolytic bone cancer (Clohisy et al., 1995, 1996). Mice with bone cancer exhibit painful behavior in the form of guarding of the affected limb, and this behavior correlates with the extent of bone destruction. Severe acute pain is also observed in mice once significant bone destruction has occurred, because normally nonnoxious palpation of the affected bone results in behaviors indicative of severe pain, and this severe pain is again correlated with the extent of bone destruction. These results suggest that this murine model shares key features with human bone cancerinduced pain.
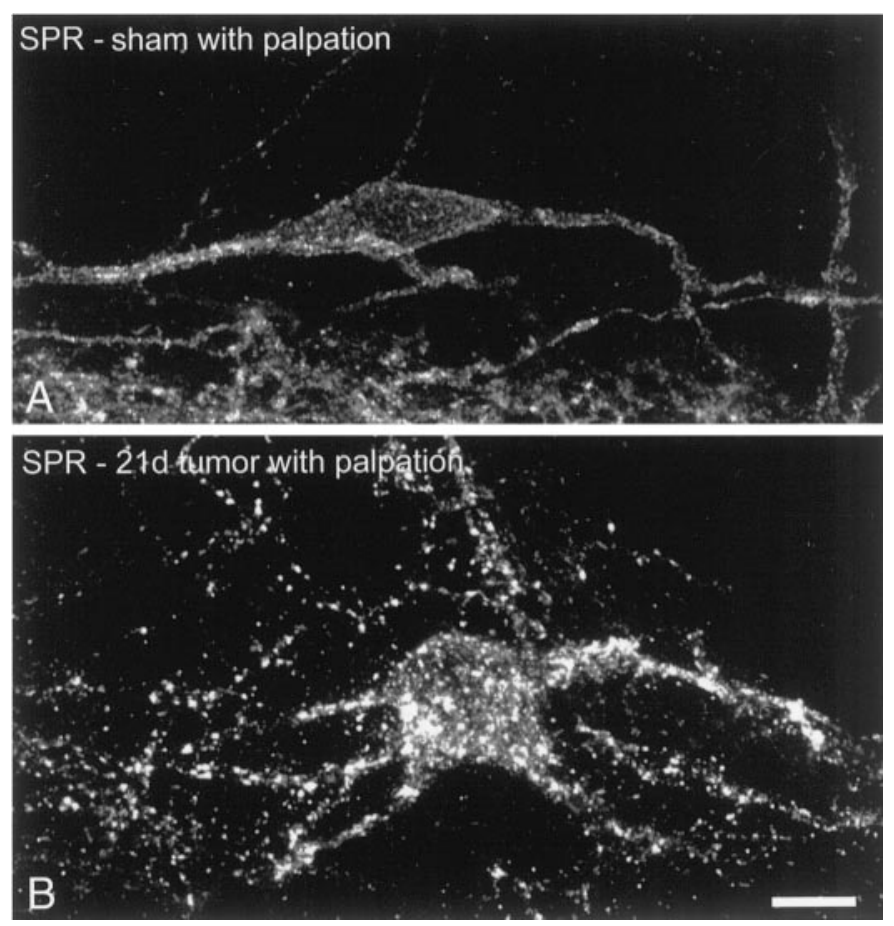

Figure 5. Normally non-noxious palpation of the knee induces SPR internalization in lamina I in animals with osteolytic sarcoma cells injected into the femur but not in sham-injected animals. Confocal images of lamina I SPR neurons in the spinal cord ipsilateral to the sham-injected femur $(A)$ and osteolytic sarcoma cell-injected femur $(B)$. In these photomicrographs the SPR, when internalized, is seen concentrated in bright endosomes inside the cytoplasm. Note that whereas innocuous palpation does not induce SPR internalization in sham-injected animals $(A)$, this same stimulation induces massive SPR internalization in animals that have significant bone destruction induced by the osteolytic sarcoma cells $(B)$. These images, from $60-\mu \mathrm{m}$-thick tissue sections, are projected from 18 optical sections acquired at $0.8 \mu \mathrm{m}$ intervals with a $100 \times$ lens. Scale bar, $10 \mu \mathrm{m}$.

\section{What factors contribute to bone cancer pain?}

In both experimental animals and humans, primary afferent sensory neurons innervate mineralized bone and the periosteum, a fibrous tissue covering the outside surface of the bone. What is clear from the present and previous studies is that while mineralized bone and the marrow are innervated by sensory neurons, this innervation is sparse compared to the sensory innervation of the periosteum (Bjurholm et al., 1988a,b; Kruger et al., 1989; Hill and Elde, 1991; Weihe et al., 1991; Hukkanen et al., 1992; Tabarowski et al., 1996). The sensory innervation of the tumor itself has been explored in the present and previous studies, and the general conclusions from these studies is that while the occasional sensory fiber can be observed innervating the tumor, this innervation is sparse and when present, is usually associated with the blood vessels that vascularize the tumor (O'Connell et al., 1998).

In light of the sensory innervation of the bone and periosteum and our understanding of tumor and bone biology, what drives bone cancer pain and why does this type of pain increase so dramatically over time? Most osteolytic tumors release a variety of factors that induce excessive osteoclast activity (Taube et al., 1994; Yoneda et al., 1994; Clohisy et al., 1995, 1996a,b; Clohisy and Ramnaraine, 1998). Osteoclasts destroy bone by forming an acidic extracellular compartment at sites of bone resorption.

With continued tumor-driven osteoclast bone resorption, the 


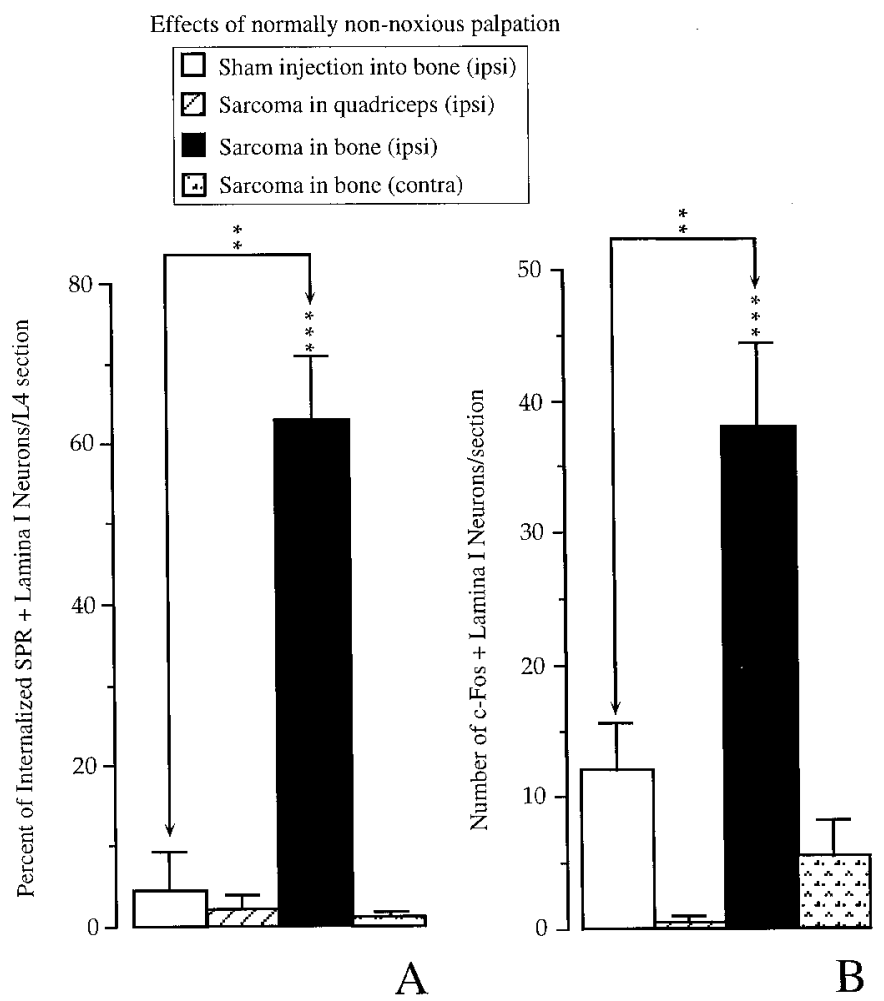

Figure 6. Normally non-noxious mechanical stimulation induces SPR internalization and c-Fos expression in lamina I spinal neurons ipsilateral to the femur injected with osteolytic sarcoma cells. Results are expressed as number of c-Fos-expressing neurons $(A)$ and percentage of internalized SPR-expressing neurons $(B)$ in lamina I after normally non-noxious mechanical stimulation (palpation) $21 \mathrm{~d}$ after media injection (sham), sarcoma injection into the quadriceps muscle, or sarcoma injection into the femur (mean $\pm \mathrm{SEM}$ ). Note that palpation does not induce spinal c-Fos expression or SPR internalization in sham animals or in animals injected with sarcoma cells into the quadriceps muscle, but does in animals with sarcoma cells injected into the femur $[p<0.01$ compared to sham animals with palpation and $p<0.001$ compared to contralateral side (sham injection without palpation)]. One-way ANOVA and Fisher's PLSD; ${ }^{* *} p<0.01,{ }^{* * *} p<0.001$ compared to the contralateral side.

osteoclasts and tumor cells may increasingly come in contact with sensory nerve fibers in the bone and the richly innervated periosteum. Many primary afferent neurons that innervate the periosteum have been shown to express acid-sensing ion channels (Olson et al., 1998) and it is probable that the decrease in $\mathrm{pH}$ produced by both nearby osteoclasts $(\mathrm{pH} 4.5-4.8$; Delaisse and Vaes, 1992) and tumor cells, which can maintain a slightly acidic extracellular pH (between 6.0 and 7.0, Griffiths, 1991; Gillies et al., 1994), directly sensitize and/or excite periosteal primary afferent fibers. In addition, tumor cells release an array of growth factors, cytokines, and chemokines, many of which have been reported to also directly excite an/or sensitize primary afferent fibers (Goni and Tolis, 1993; Suzuki and Yamada, 1994; Watkins et al., 1994; Safieh-Garabedian et al., 1995; Woolf et al., 1997).

In the present study, we used two markers, SPR internalization and c-Fos expression in lamina I neurons, to indirectly demonstrate that primary afferent neurons are sensitized after extensive tumor-induced bone destruction. In previous studies, it has been shown that, whereas in the normal animal, only noxious stimulation results in the release of SP and the subsequent internalization of the SPR in lamina I neurons, in animals with either persistent inflammatory or neuropathic pain, normally non- noxious or noxious somatosensory stimulation now induces SPR internalization in lamina I neurons (Mantyh et al., 1995; Allen et al., 1997; Abbadie et al., 1997b; Honore et al., 1999). Similarly, whereas in the normal animal, noxious stimulation is required to induce c-Fos expression in lamina I neurons (Hunt et al., 1987; Abbadie and Besson, 1993; Jasmin et al., 1994; Basbaum, 1994; Honore et al., 1995a; Doyle and Hunt, 1999), after extensive bone destruction, non-noxious palpation of the tumorous bone induces c-Fos expression. These data suggest that there is sensitization of primary afferent neurons in animals with bone cancer, and this sensitization is correlated with the extent of bone destruction and growth of the tumor.

Bone cancer also induces a profound reorganization of the spinal cord that may be reflective of a central sensitization that is frequently observed in persistent pain states. In the segments of the spinal cord that receive primary afferent input from the bone with cancer, and only in these segments, we observed massive astrocyte hypertrophy without neuronal loss and expression of the pro-hyperalgesic peptide dynorphin and c-Fos protein in a population of neurons located in the deep spinal laminae. What is remarkable about these alterations is the magnitude and localized nature of these changes in terms of spinal cord segments and being almost exclusively ipsilateral to the side of bone destruction.

Hypertrophy of spinal astrocytes has previously been reported after sciatic nerve injury (Garrison et al., 1991, 1994; Colburn et al., 1997). However, examination of the sciatic nerve that innervates the femur with cancer revealed no sign of direct physical injury, and astrocyte hypertrophy was not observed in shaminjected animals or when the tumor was growing exclusively outside the bone. Whether the massive astrocyte hypertrophy is involved in the generation and maintenance of bone cancer pain is unclear (Meller et al., 1994), but it has previously been shown that astrocytes express glutamate-aspartate transporters and thus are intimately involved in regulating the extracellular levels of excitatory amino acids (Hansson and Rönnbäck, 1991; Amundson et al., 1992; Levi and Patrizio, 1992; Miyake and Kitamura, 1992; Shao and McCarthy, 1994; Shibata et al., 1997; Sonnewald et al., 1997; Lehre and Danbolt, 1998). Additionally, astrocytes that have undergone hypertrophy have been shown to release a variety of cytokines and growth factors that can dramatically alter the surrounding neurochemical environment (Gadient et al., 1990; Aloisi et al., 1992; Constam et al., 1992; Maimone et al., 1993; Murphy et al., 1993; Pechán et al., 1993; Maeda et al., 1994; Schettini et al., 1994; Grimaldi et al., 1995, 1997, 1998; Corsini et al., 1996; Derocq et al., 1996; Hori et al., 1996; Kossmann et al., 1996; Shafer and Murphy, 1997; Bruno et al., 1998; Sinor et al., 1998). Indeed, the population of neurons that show upregulation of the pro-hyperalgesic neuropeptide dynorphin and increased c-Fos expression are in the deep laminae and in close proximity to the astrocytes showing marked hypertrophy. Although changes in c-Fos and especially dynorphin have been associated with changes observed in inflammatory and neuropathic pain states (Iadarola et al., 1988a,b; Ruda et al., 1988; Weihe et al., 1988; Draisci and Iadarola, 1989; Noguchi et al., 1991; Abbadie and Besson, 1992; Wagner et al., 1993; Honore et al., 1995a,b; Abbadie et al., 1997b; Nichols et al., 1997; Catheline et al., 1999), these data suggest that bone cancer induces a profound neurochemical reorganization of the spinal cord that is directly correlated with the extent of cancer-induced bone destruction. 


\section{Neurochemical signature of inflammatory, neuropathic, and bone cancer pain}

In recent years, significant progress has been made in demonstrating that in different persistent pain states there are strikingly different neurochemical changes that occur in primary afferent neurons and the spinal cord (Hokfelt et al., 1994). These neurochemical differences mirror the fact that many analgesics are most efficacious in blocking a specific type of persistent pain (Fields, 1988, 1989). For example, morphine is efficacious in treating inflammatory pain, but not neuropathic pain caused by peripheral nerve injury (Ossipov et al., 1995a,b), and gabapentin is frequently effective in treating neuropathic but not inflammatory pain.

In comparing bone cancer pain to inflammatory or neuropathic pain, both the neurochemical changes that take place and the analgesics that are most effective in treating humans suggest that the mechanisms involved in the generation and maintenance of bone cancer pain are unique. For example, whereas SP levels in primary afferent neurons rise in inflammatory pain (Lembeck et al., 1981; Donaldson et al., 1992) and decrease in neuropathic pain (Noguchi et al., 1989; Garrison et al., 1993), they are not altered in bone cancer pain. Even more striking are the changes observed in astrocyte hypertrophy in the spinal cord. Astrocyte hypertrophy in the spinal cord is uncommon in most models of inflammatory pain and is only observed in neuropathic pain states when there has been significant injury to the peripheral nerve (Garrison et al., 1991, 1994). In contrast, although there is no evidence of direct injury to the peripheral nerve, massive astrocyte hypertrophy is observed in the bone cancer model.

The unique neurochemical reorganization of the spinal cord in bone cancer is mirrored by the clinical experience that analgesics that are efficacious in the relief of inflammatory or neuropathic pain are frequently ineffective at relieving advanced bone cancer pain. Understanding the distinct neurochemical events that are involved in the generation and maintenance of different persistent pain states should provide a mechanistic approach for understanding and developing novel therapies for unique persistent pain states such as cancer pain.

\section{REFERENCES}

Abbadie C, Besson J-M (1992) c-Fos expression in rat lumbar spinal cord during the development of adjuvant-induced arthritis. Neuroscience 48:985-993.

Abbadie C, Besson J-M (1993) c-Fos expression in rat lumbar spinal cord following peripheral stimulation in adjuvant-induced arthritis and in normal rats. Brain Res 607:195-204.

Abbadie C, Taylor BK, Peterson MA, Basbaum AI (1997a) Differential contribution of the two phases of the formalin test to the pattern of c-Fos expression in the rat spinal cord: studies with remifentanil and lidocaine. Pain 69:101-110.

Abbadie C, Trafton J, Liu H, Mantyh PW, Basbaum AI (1997b) Inflammation increases the distribution of dorsal horn neurons that internalize the neurokinin-1 receptor in response to noxious and non-noxious stimulation. J Neurosci 17:8049-8060.

Adami S (1997) Bisphosphonates in prostate carcinoma. Cancer 80:1674-1679.

Allen BJ, Rogers SD, Ghilardi JR, Menning PM, Kuskowski MA, Basbaum AI, Simone DA, Mantyh PW (1997) Noxious cutaneous thermal stimuli induce a graded release of endogenous substance $\mathrm{P}$ in the spinal cord: imaging peptide action in vivo. J Neurosci 17:5921-5927.

Aloisi F, Care A, Borsellino G, Gallo P, Rosa S, Bassani A, Cabibbo A, Testa U, Levi G, Peschle C (1992) Production of hemolymphopoietic cytokines (IL-6, IL-8, colony-stimulating factors) by normal human astrocytes in response to IL-1 beta and tumor necrosis factor-alpha. J Immunol 149:2358-2366.
Amundson RH, Goderie SK, Kimelberg HK (1992) Uptake of $\left[{ }^{3} \mathrm{H}\right] \mathrm{se}$ rotonin and $\left[{ }^{3} \mathrm{H}\right]$ glutamate by primary astrocyte cultures. II. Differences in cultures prepared from different brain regions. Glia 6:9-18.

Banning A, Sjogren P, Henriksen H (1991) Pain causes in 200 patients referred to a multidisciplinary cancer pain clinic. Pain 45:45-48.

Basbaum AI (1994) Immediate-early genes and pain: what's all the "Fos" about? APS Journal 3:49-52.

Bjurholm A, Kreicbergs A, Brodin E, Schultzberg M (1988a) Substance P- and CGRP-immunoreactive nerves in bone. Peptides 9:165-171.

Bjurholm A, Kreicbergs A, Terenius L, Goldstein M, Schultzberg M (1988b) Neuropeptide Y-, tyrosine hydroxylase- and vasoactive intestinal polypeptide-immunoreactive nerves in bone and surrounding tissues. J Auton Nerv Syst 25:119-125.

Bruno V, Battaglia G, Casabona G, Copani A, Caciagli F, Nicoletti F (1998) Neuroprotection by glial metabotropic glutamate receptors is mediated by transforming growth factor-beta. J Neurosci 18:9594-9600.

Catheline G, Le Guen S, Honore P, Besson J-M (1999) Are there long-term changes in the basal or evoked Fos expression in the dorsal horn of the spinal cord of the mononeuropathic rat? Pain 80:347-57.

Clohisy DR, Ogilvie CM, Ramnaraine ML (1995) Tumor osteolysis in osteopetrotic mice. J Orthop Res 13:892-897.

Clohisy DR, Ogilvie CM, Carpenter RJ, Ramnaraine ML (1996a) Localized, tumor-associated osteolysis involves the recruitment and activation of osteoclasts. J Orthop Res 14:2-6.

Clohisy DR, Palkert D, Ramnaraine ML, Pekurovsky I, Oursler MJ (1996b) Human breast cancer induces osteoclast activation and increases the number of osteoclasts at sites of tumor osteolysis. J Orthop Res 14:396-402.

Clohisy DR, Ramnaraine ML (1998) Osteoclasts are required for bone tumors to grow and destroy bone. J Orthop Res 16:660-666.

Colburn RW, DeLeo JA, Rickman AJ, Yeager MP, Kwon P, Hickey WF (1997) Dissociation of microglial activation and neuropathic pain behavior following peripheral nerve injury in the rat. J Neuroimmunol 79:163-175.

Coleman RE (1998) How can we improve the treatment of bone metastases further? Curr Opin Oncol 10:S7-S13.

Coleman RE, Rubens RD (1985) Bone metastases and breast cancer. Cancer Treat Rev 12:251-270.

Coleman RE, Rubens RD (1987) The clinical course of bone metastases from breast cancer. Br J Cancer 55:61-66.

Constam DB, Philipp J, Malipiero UV, Dijke P, Schachner M, Fontana A (1992) Differential expression of transforming growth factor-beta 1, -beta 2, and -beta 3 by glioblastoma cells, astrocytes, and microglia. J Immunol 148:1404-1410.

Corsini E, Dufour A, Ciusani E, Gelati M, Frigerio S, Gritti A, Cajola L, Mancardi GL, Massa G, Salmaggi A (1996) Human brain endothelial cells and astrocytes produce IL-1 beta but not IL-10. Scand J Immunol 44:506-511.

Coukell AJ, Markham A (1998) Pamidronate. A review of its use in the management of osteolytic bone metastases, tumour-induced hypercalcaemia and Paget's disease of bone. Drugs Aging 12:149-168.

Delaisse J-M, Vaes G (1992) Mechanism of mineral solubilization and matrix degradation in osteoclastic bone resorption. In: Biology and physiology of the osteoclast (Rifkin BR, Gay CV, eds) pp 289-314. Ann Arbor: CRC.

Derocq JM, Segui M, Blazy C, Emonds-Alt X, Le Fur G, Brelire JC, Casellas P (1996) Effect of substance P on cytokine production by human astrocytic cells and blood mononuclear cells: characterization of novel tachykinin receptor antagonists. FEBS Lett 399:321-325.

Donaldson LF, Harmar AJ, McQueen DS, Seckl JR (1992) Increased expression of preprotachykinin, calcitonin gene-related peptide, but not vasoactive intestinal peptide messenger RNA in dorsal root ganglia during the development of adjuvant monoarthritis in the rat. Mol Brain Res 16:143-149.

Doyle CA, Hunt SP (1999) Substance P receptor (neurokinin-1)expressing neurons in lamina I of the spinal cord encode for the intensity of noxious stimulation: a c-Fos study in rat. Neuroscience 89:17-28.

Draisci G, Iadarola MJ (1989) Temporal analysis of increases in c-Fos, preprodynorphin and preproenkephalin mRNAs in rat spinal cord. Mol Brain Res 6:31-37.

Fields HL (1988) Can opiates relieve neuropathic pain? Pain 35:365-367.

Fields HL (1989) Pain modulation: opiates and chronic pain. NIDA Res Monogr 95:92-101. 
Foley KM (1999) Advances in cancer pain. Arch Neurol 56:413-417. Fulfaro F, Casuccio A, Ticozzi C, Ripamonti C (1998) The role of bisphosphonates in the treatment of painful metastatic bone disease: a review of phase III trials. Pain 78:157-169.

Gadient RA, Cron KC, Otten U (1990) Interleukin-1 beta and tumor necrosis factor-alpha synergistically stimulate nerve growth factor (NGF) release from cultured rat astrocytes. Neurosci Lett 117:335-340.

Garrison CJ, Dougherty PM, Kajander KC, Carlton SM (1991) Staining of glial fibrillary acidic protein (GFAP) in lumbar spinal cord increases following a sciatic nerve constriction injury. Brain Res 565:1-7.

Garrison CJ, Dougherty PM, Carlton SM (1993) Quantitative analysis of substance $\mathrm{P}$ and calcitonin gene-related peptide immunohistochemical staining in the dorsal horn of neuropathic MK-801-treated rats. Brain Res 607:205-214.

Garrison CJ, Dougherty PM, Carlton SM (1994) GFAP expression in lumbar spinal cord of naive and neuropathic rats treated with MK-801. Exp Neurol 129:237-243.

Gillies RJ, Liu Z, Bhujwalla Z (1994) 31P-MRS measurements of extracellular $\mathrm{pH}$ of tumors using 3-aminopropylphosphonate. Am Physiol Soc 267:C195-C203.

Goni MH, Tolis G (1993) Hypercalcemia of cancer: an update. Anticancer Res 13:1155-1160.

Griffiths JR (1991) Are cancer cells acidic? Br J Cancer 64:425-427.

Grimaldi M, Arcone R, Ciliberto G, Schettini G (1995) Synergistic stimulation of interleukin- 6 release and gene expression by phorbol esters and interleukin- 1 beta in rat cortical astrocytes: role of protein kinase C activation and blockade. J Neurochem 64:1945-1953.

Grimaldi M, Florio T, Schettini G (1997) Somatostatin inhibits interleukin-6 release from rat cortical type I astrocytes via the inhibition of adenylyl cyclase. Biochem Biophys Res Commun 235:242-248.

Grimaldi M, Navarra P, Pozzoli G, Preziosi P, Schettini G (1998) Bacterial lipopolysaccharide increases interleukin-6 and prostaglandin release in rat cortical type I astrocytes by different mechanisms: role of anti-inflammatory agents. Biochem Biophys Res Commun 250:798-804.

Hansson E, Rönnbäck L (1991) Receptor regulation of the glutamate, GABA and taurine high-affinity uptake into astrocytes in primary culture. Brain Res 548:215-221.

Hill EL, Elde R (1991) Distribution of CGRP-, VIP-, DbH-, SP-, and NPY-immunoreactive nerves in the periosteum of the rat. Cell Tissue Res 264:469-480.

Hingtgen CM, Vasko MR (1994) Prostacyclin enhances the evokedrelease of substance $\mathrm{P}$ and calcitonin gene-related peptide from rat sensory neurons. Brain Res 655:51-60.

Hingtgen CM, Waite KJ, Vasko MR (1995) Prostaglandins facilitate peptide release from rat sensory neurons by activating the adenosine $3^{\prime}, 5^{\prime}$-cyclic monophosphate transduction cascade. J Neurosci 15:5411-5419.

Hokfelt T, Zhang X, Wiesenfeld-Hallin Z (1994) Messenger plasticity in primary sensory neurons following axotomy and its functional implications. Trends Neurosci 17:22-30.

Honore P, Buritova J, Besson J-M (1995a) Carrageenin-evoked c-Fos expression in rat lumbar spinal cord: the effects of indomethacin. Eur J Pharmacol 272:249-259.

Honore P, Chapman V, Buritova J, Besson J-M (1995b) Reduction of carrageenin oedema and the associated c-Fos expression in the rat lumbar spinal cord by nitric oxide synthase inhibitor. Br J Pharmacol 114:77-84.

Honore P, Menning PM, Rogers SD, Nichols ML, Basbaum AI, Besson J-M, Mantyh PW (1999) Spinal substance P receptor expression and internalization in acute, short-term, and long-term inflammatory pain states. J Neurosci 19:7670-7678.

Hori O, Matsumoto M, Kuwabara K, Maeda Y, Ueda H, Ohtsuki T, Kinoshita T, Ogawa S, Stern DM, Kamada T (1996) Exposure of astrocytes to hypoxia/reoxygenation enhances expression of glucoseregulated protein 78 facilitating astrocyte release of the neuroprotective cytokine interleukin-6. J Neurochem 66:973-979.

Hukkanen M, Konttinen YT, Rees RG, Santavirta S, Terenghi G, Polak JM (1992) Distribution of nerve endings and sensory neuropeptides in rat synovium, meniscus and bone. Int J Tissue React 14:1-10.

Hunt SP, Pini A, Evan G (1987) Induction of $c$-Fos-like protein in spinal cord neurons following sensory stimulation. Nature 328:632-634.

Iadarola MJ, Brady LS, Draisci G, Dubner R (1988a) Enhancement of dynorphin gene expression in spinal cord following experimental in- flammation: stimulus specificity, behavioral parameters and opioid receptor binding. Pain 35:313-326.

Iadarola MJ, Douglass J, Civelli O, Naranjo JR (1988b) Differential activation of spinal cord dynorphin and enkephalin neurons during hyperalgesia: evidence using cDNA hybridization. Brain Res 455:205-212.

Iwasaki A, Inoue K, Hukuda S (1995) Distribution of neuropeptidecontaining nerve fibers in the synovium and adjacent bone of the rat knee joint. Clin Exp Rheumatol 13:173-178.

Jasmin L, Wang H, Tarczy-Hornoch K, Levine JD, Basbaum AI (1994) Differential effects of morphine on noxious stimulus-evoked fos-like immunoreactivity in subpopulations of spinoparabrachial neurons. J Neurosci 14:7252-7260.

Koeller JM (1990) Understanding cancer pain. Am J Hosp Pharm 47:S3-S6.

Kossmann T, Hans V, Imhof HG, Trentz O, Morganti-Kossmann MC (1996) Interleukin-6 released in human cerebrospinal fluid following traumatic brain injury may trigger nerve growth factor production in astrocytes. Brain Res 713:143-152.

Kruger L, Silverman JD, Mantyh PW, Sternini C, Brecha NC (1989) Peripheral patterns of calcitonin-gene-related peptide general somatic sensory innervation: cutaneous and deep terminations. J Comp Neurol 280:291-302.

LaMotte C, Kapadia SE, Shapiro CM (1991) Central projections of the sciatic, saphenous, median, and ulnar nerves of the rat demonstrated by transganglionic transport of choleragenoid-HRP (B-HRP) and wheat germ agglutinin-HRP (WGA-HRP). J Comp Neurol 311:546-562.

Lehre KP, Danbolt NC (1998) The number of glutamate transporter subtype molecules at glutamatergic synapses: chemical and stereological quantification in young adult rat brain. J Neurosci 18:8751-8757.

Lembeck F, Donnerer J, Colpaert FC (1981) Increase of substance P in primary afferent nerves during chronic pain. Neuropeptides 1:175-180.

Levi G, Patrizio M (1992) Astrocyte heterogeneity: endogenous amino acid levels and release evoked by non- $N$-methyl-D-aspartate receptor agonists and by potassium-induced swelling in type- 1 and type- 2 astrocytes. J Neurochem 58:1943-1952.

Lipton A (1997) Bisphosphonates and breast carcinoma. Cancer 80:1668-1673.

Maeda Y, Matsumoto M, Hori O, Kuwabara K, Ogawa S, Yan SD, Ohtsuki T, Kinoshita T, Kamada T, Stern DM (1994) Hypoxia/ reoxygenation-mediated induction of astrocyte interleukin-6: a paracrine mechanism potentially enhancing neuron survival. J Exp Med 180:2297-2308.

Maimone D, Cioni C, Rosa S, Macchia G, Aloisi F, Annunziata P (1993) Norepinephrine and vasoactive intestinal peptide induce IL-6 secretion by astrocytes: synergism with IL-1 beta and TNF alpha. J Neuroimmunol 47:73-81.

Mantyh PW, DeMaster E, Malhotra A, Ghilardi JR, Rogers SD, Mantyh CR, Liu H, Basbaum AI, Vigna SR, Maggio JE, Simone DA (1995) Receptor endocytosis and dendrite reshaping in spinal neurons after somatosensory stimulation. Science 268:1629-1632.

McBride WH (1986) Phenotype and functions of intratumoral macrophages. Biochim Biophys Acta 865:27-41.

Meller ST, Dykstra C, Grzybycki D, Murphy S, Gebhart GF (1994) The possible role of glia in nociceptive processing and hyperalgesia in the spinal cord of the rat. Neuropharmacology 33:1471-1478.

Mercadante S (1997) Malignant bone pain: pathophysiology and treatment. Pain 69:1-18.

Mercadante S, Arcuri E (1998) Breakthrough pain in cancer patients: pathophysiology and treatment. Cancer Treat Rev 24:425-432.

Miyake T, Kitamura T (1992) Glutamine synthetase immunoreactivity in two types of mouse brain glial cells. Brain Res 586:53-60.

Molander C, Grant G (1985) Cutaneous projections from the rat hindlimb foot to the substantia gelatinosa of the spinal cord studied by transganglionic transport of WGA-HRP conjugate. J Comp Neurol 237:476-484.

Molander C, Xu Q, Grant G (1984) The cytoarchitectonic organization of the spinal cord in the rat: I. The lower thoracic and lumbosacral cord. J Comp Neurol 230:133-141.

Mundy GR (1988) Hypercalcemia of malignancy revisited. J Clin Invest 82:1-6.

Mundy GR (1997) Mechanisms of bone metastasis. Cancer 80:1546-1556.

Murphy TH, Blatter LA, Wier WG, Baraban JM (1993) Rapid commu- 
nication between neurons and astrocytes in primary cortical cultures. J Neurosci 13:2672-2679.

Nichols ML, Lopez Y, Ossipov MH, Bian D, Porreca F (1997) Enhancement of the antiallodynic and antinociceptive efficacy of spinal morphine by antisera to dynorphin A. Pain 69:317-322.

Noguchi K, Senba E, Morita Y, Sato M, Tohyama M (1989) Prepro-VIP and preprotachykinin mRNAs in the rat dorsal root ganglion cells following peripheral axotomy. Mol Brain Res 6:327-330.

Noguchi K, Kowalski K, Traub R, Solodkin A, Iadarola MJ, Ruda MA (1991) Dynorphin expression and Fos-like immunoreactivity following inflammation induced hyperalgesia are colocalized in spinal cord neurons. Mol Brain Res 10:227-233.

O'Connell JX, Nanthakumar SS, Nielsen GP, Rosenberg AE (1998) Osteoid osteoma: the uniquely innervated bone tumor. Modern Pathol 11:175-180.

Olson TH, Rield MS, Vulchanova XR, Elde R (1998) An acid sensing ion channel (ASIC) localizes to small primary afferent neurons in rats. NeuroReport 9:1109-1113.

Ossipov MH, Lopez Y, Nichols ML, Bian D, Porreca F (1995a) Inhibition by spinal morphine of the tail-flick response is attenuated in rats with nerve ligation injury. Neurosci Lett 199:83-86.

Ossipov MH, Lopez Y, Nichols ML, Bian D, Porreca F (1995b) The loss of antinociceptive efficacy of spinal morphine in rats with nerve ligation injury is prevented by reducing spinal afferent drive. Neurosci Lett 199:87-90.

Pechán PA, Chowdhury K, Gerdes W, Seifert W (1993) Glutamate induces the growth factors NGF, $\beta \mathrm{FGF}$, the receptor FGF-R1 and c-fos mRNA expression in rat astrocyte culture. Neurosci Lett 153:111-114.

Portenoy RK, Lesage P (1999) Management of cancer pain. Lancet 353:1695-1700.

Portenoy RK, Payne D, Jacobsen P (1999) Breakthrough pain: characteristics and impact in patients with cancer pain. Pain 81:129-134.

Ruda MA, Iadarola MJ, Cohen LV, Young WS (1988) In situ hybridization histochemistry and immunocytochemistry reveal an increase in spinal dynorphin biosynthesis in a rat model of peripheral inflammation and hyperalgesia. Proc Natl Acad Sci USA 85:622-626.

Safieh-Garabedian B, Poole S, Allchorne A, Winter J, Woolf CJ (1995) Contribution of interleukin-1 beta to the inflammation-induced increase in nerve growth factor levels and inflammatory hyperalgesia. Br J Pharmacol 115:1265-1275.

Schettini G, Grimaldi M, Navarra P, Pozzoli G, Reichlin S, Preziosi P (1994) Regulation of interleukin-6 production by cAMP-protein kinase-A pathway in rat cortical astrocytes. Pharmacol Res 30:13-24.

Shafer RA, Murphy S (1997) Activated astrocytes induce nitric oxide synthase-2 in cerebral endothelium via tumor necrosis factor alpha. Glia 21:370-379.

Shao Y, McCarthy KD (1994) Plasticity of astrocytes. Glia 11:147-155. Shibata T, Yamada K, Watanabe M, Ikenaka K, Wada K, Tanaka K,
Inoue Y (1997) Glutamate transporter GLAST is expressed in the radial glia-astrocyte lineage of developing mouse spinal cord. J Neurosci 17:9212-9219.

Sinor AD, Irvin SM, Cobbs CS, Chen J, Graham SH, Greenberg DA (1998) Hypoxic induction of vascular endothelial growth factor (VEGF) protein in astroglial cultures. Brain Res 812:289-291.

Sonnewald U, Westergaard N, Schousboe A (1997) Glutamate transport and metabolism in astrocytes. Glia 21:56-63.

Sorkin LS, Xiao WH, Wagner R, Myers RR (1997) Tumor necrosis factor-alpha induces ectopic activity in nociceptive primary afferent fibers. Neuroscience 81:255-262.

Suzuki K, Yamada S (1994) Ascites sarcoma 180, a tumor associated with hypercalcemia, secretes potent bone-resorbing factors including transforming growth factor alpha, interleukin-1 alpha and interleukin-6. Bone Miner 27:219-233.

Tabarowski Z, Gibson-Berry K, Felten SY (1996) Noradrenergic and peptidergic innervation of the mouse femur bone marrow. Acta Histochem 98:453-457.

Taube T, Elomaa I, Blomqvist C, Beneton MN, Kanis JA (1994) Histomorphometric evidence for osteoclast-mediated bone resorption in metastatic breast cancer. Bone 15:161-166.

Vasko MR (1995) Prostaglandin-induced neuropeptide release from spinal cord. Prog Brain Res 104:367-380.

Vasko MR, Campbell WB, Waite KJ (1994) Prostaglandin E2 enhances bradykinin-stimulated release of neuropeptides from rat sensory neurons in culture. J Neurosci 14:4987-4997.

Wagner R, DeLeo JA, Coombs DW, Willenbring S, Fromm C (1993) Spinal dynorphin immunoreactivity increases bilaterally in a neuropathic pain model. Brain Res 629:323-326.

Watkins LR, Wiertelak EP, Goehler LE, Smith KP, Martin D, Maier SF (1994) Characterization of cytokine-induced hyperalgesia. Brain Res 654:15-26.

Weihe E, Millan MJ, Leibold A, Nohr D, Herz A (1988) Colocalization of pro-enkephalin and pro-dynorphin-derived opioid peptides in laminae IV/V spinal neurons revealed in arthritic rats. Neurosci Lett $85: 187-192$.

Weihe E, Nohr D, Michel S, Muller S, Zentel HJ, Fink T, Krekel J (1991) Molecular anatomy of the neuro-immune connection. Int $\mathrm{J}$ Neurosci 59:1-23.

Witzel JG, Bohndorf K, Prescher A, Adam G (1992) Osteosarcoma of the nude rat. A model for experimental magnetic resonance. Invest Radiol 27:205-210.

Woolf CJ, Allchorne A, Safieh-Garabedian B, Poole S (1997) Cytokines, nerve growth factor and inflammatory hyperalgesia: the contribution of tumour necrosis factor alpha. Br J Pharmacol 121:417-424.

Yoneda T, Sasaki A, Mundy GR (1994) Osteolytic bone metastasis in breast Yoshida K, Toya S (1997) Neurotrophic activity in cytokineactivated astrocytes. Keio J Med 46:55-60. 